\title{
XX Historias del siglo veinte chileno
}

\author{
Andrés Baeza, Andrés Estefane, Juan Luis \\ Ossa, Joaquín Fernández, Cristóbal García- \\ Huidobro, Nicolás Ocaranza y Pablo Moscoso
}
Santiago, Ediciones B Chile S.A, 2008, 1era edición, 492 págs.

\section{Jorge Gaete Lagos*}

Recibido: 20.04.2010

Aceptado: 16.06.2010

$* * *$

El presente libro constituye una interesante propuesta para enfrentar el estudio del pasado de una manera distinta a la historiografía tradicional, a la cual se la ha criticado muchas veces por su escritura compleja y por la escasa empatía que las investigaciones generan con el lector que no es especialista en este tipo de conocimientos. Es por esto que, y al igual que lo realizado en XIX Historias del siglo diecinueve chileno, los autores del texto presentan una serie de artículos en los que predomina un lenguaje cercano y directo, con el fin de llegar a un público mucho más amplio.

A lo largo de sus páginas, los autores nos presentan siete episodios ocurridos a lo largo del siglo XX chileno. Para Fernando Purcell, redactor del prólogo del texto, abordar esta época constituye un acierto, ya que se logra rebatir la idea de que la identidad nacional terminó por construirse en la Guerra del Pacífico. Por ello, destaca que este proceso se ha mantenido vigente, y que hoy, en medio de las celebraciones del Bicentenario, representa un tema que vale la pena discutir.

El libro comienza con el artículo de Andrés Baeza, en el cual analiza a Chile en el año 1910, basándose en las ideas de "superstición y "muerte” que predominaron en tal período. Su estudio lo empieza abordando el paso del cometa Halley durante el mes de mayo, y menciona las predicciones que rodearon su visita, las que provenían de la comunidad astronómica y de la población en general. De esta forma, destaca algunos estudios realizados como los del astrónomo francés Camille Flammarion, que indicaban que sus gases venenosos podrían provocar graves daños al planeta o incluso el fin del mundo, y recoge también algunos testimonios de chilenos que

*UNAB, Santiago, Chile. Email: jlgaete_reload@hotmail.com 
fueron testigos de su paso por el firmamento, a los cuales los invadió una mezcla de sentimientos que oscilaban entre la incertidumbre, la expectación y el miedo.

Estas sensaciones son recogidas por Baeza, con el propósito de retratar el estado de ánimo que pudieron haber tenido los chilenos de esa época. Para ello, concluye su estudia analizando ciertos acontecimientos “trágicos” que precedieron a la celebración del centenario de nuestro país. Entre estos, menciona la “Cuestión Social”, resaltando las críticas que los intelectuales de la época realizaron al sistema por la ineficacia mostrada para solucionar los problemas de la clase trabajadora.

Los otros hechos corresponden a una situación inédita ocurrida en Chile, que fue la muerte del Presidente de la República Pedro Montt en la ciudad alemana de Bremen durante el mes de agosto, y la de su amigo, ministro del interior y reemplazante provisional Elías Fernández Albano, ocurrida en septiembre a causa de una infección al pulmón. Esto provocó que el ministro de Justicia Emiliano Figueroa Larraín asumiera el cargo, por ser el más antiguo del gabinete, y fue finalmente el encargado de liderar las celebraciones del centenario, ya que el canciller Luis Izquierdo no quiso asumir el cargo a pesar de que le correspondía por ley.

Por su parte, Andrés Estefane exhibe un estudio en el que rescata al ser humano escondido tras la obra de Nicanor Parra "Sermones y prédicas del Cristo de Elqui”, publicada en 1977. En su análisis, este autor deja de lado la imagen poética del personaje, con el fin de rescatar al ser humano que esta encerraba y así construir un verdadero relato historiográfico. Para lograr esto, estudia la vida y obra del profeta Domingo Zárate Vega, más conocido como el "Cristo" del valle del Elqui, el que se hizo famoso por autodenominarse enviado de Dios y por predicar en lugares como Vicuña, La Serena y Valparaíso en la década de 1930, en las que pretendía mostrar sus supuestos dones de curandero y sus capacidades para volar, las cuales nunca se llevaron a cabo. Sin embargo, Zárate seguía intentándolo, ya que culpaba de sus fracasos a la supuesta "poca fe" de sus seguidores, a los que conminaba a seguir rezando.

De esta forma, el ensayo de Estefane resulta ser muy interesante, ya que establece sus conjeturas a partir de la "extravagancia” que rodeaba la figura del Cristo de Elqui, evitando la tendencia a tildarlo inmediatamente como un loco. Además, el autor menciona una serie de elementos, tales como las conversaciones que el profeta tuvo con Dios, sus recorridos alrededor de Chile, sus pensamientos filosóficos, entre otros, con el fin de recoger la vida y obra de tan singular personaje.

El tercer artículo del texto está escrito por Juan Luis Ossa, el cual estudia la expansión de la ideología nacional-socialista en Chile, la que provocó la creación del movimiento "nacista”, que seguía tales postulados. Además, analiza la figura de Jorge González Von Marées, líder de este grupo, y también busca intercalar la serie de sucesos que rodearon la ma- 
tanza en el edificio del seguro obrero en 1938.

A lo largo de su artículo, Ossa destaca la polarización política que vivía nuestro país en la década de 1930, y menciona cómo los nacistas pretendieron, ante la crisis que había mostrado el Estado liberal, ser una tercera alternativa ante la vieja oligarquía y la creciente corriente marxista, siendo una opción que pretendió consolidarse en las elecciones presidenciales de 1938 al llevar como candidato al general Carlos Ibáñez. También menciona que los nacistas, ante la amenaza del triunfo del conservador Gustavo Ross, y al no lograr aliarse con el Frente Popular, comenzaron a preparar un golpe que se desarrolló el 5 de septiembre de aquel año, el cual terminó con la matanza de aproximadamente 60 jóvenes pertenecientes a esa colectividad.

Este episodio marcó el fin del nazismo, ya que lo sucedieron algunos posteriores intentos de reunificación liderados por González de tendencia izquierdista, tales como la Vanguardia Popular Socialista, que no perduraron en el tiempo. Sin embargo, la consecuencia principal de la matanza fue que alteró el curso electoral de ese año, ya que el porcentaje de votos provenientes del nazismo permitió el estrecho triunfo de Pedro Aguirre Cerda ante Gustavo Ross.

La polarización ideológica de esta década y las elecciones de 1938 también forma parte de la cuarta investigación del texto, escrita por Joaquín Fernández. En ella, el autor analiza las consecuencias que el triunfo de Pedro Aguirre Cerda provocó para el sector conservador, el que intentó impugnar los resultados, y para el Ejército, el que mostraba suspicacias al ver que los ministros de defensa Alberto Cabero y Guillermo Labarca eran antimilitares.

En medio de este contexto, Fernández destaca la figura del general de segunda división Ariosto Herrera, el cual se hizo famoso durante el desfile del 21 de mayo de 1939 por pedir que bajaran a un individuo desde las rejas de la Moneda, y que portaba un trapo rojo, lo cual le valió las simpatías de los sectores conservadores. Sin embargo, su carrera se vio interrumpida luego de que el 8 de julio se descubriera una conspiración en contra del Frente Popular conocida como el “complot del póquer", en la que Investigaciones encontró a un grupo de civiles y militares subversivos reunidos en torno a una mesa de póquer y que planteaban una insurrección. Esto provocó las suspicacias del gobierno en contra de Herrera, ya que era abiertamente anticomunista.

Este hecho provocó la indignación de grupos civiles y militares de derecha, los cuales comenzaron a fraguar un golpe que instalaría a Herrera en la Moneda conocido como el “Ariostazo”, que comenzó a desencadenarse a través de los levantamientos en el Regimiento Tacna y en la Guarnición de Santiago, los que fueron detenidos por fuerzas militares leales al gobierno. Como consecuencia de estos actos, Ariosto Herrera fue desterrado a México. 
Posteriormente, Cristóbal García-Huidobro comparte con los lectores una antigua situación cotidiana vivida con su abuelo, el cual le dijo que no comprase el diario “El Mercurio” mentía, y que esta frase había sido popularizada en la toma de los estudiantes de la Pontificia Universidad Católica (PUC) en 1967. Utilizando este recuerdo, el autor busca reconstruir los episodios que rodearon a este movimiento, para lo cual se remonta a la década de 1960 y a la coyuntura de la PUC de aquellos años. Así, destaca que al interior de la iglesia existía una necesidad de renovación, por lo que planteaba reformular la labor de instituciones como esta casa de estudios, buscando integrar a grupos y hacer de la PUC un centro de difusión de catolicidad y cultura, en vez de formar burócratas sin contenido social.

Estas demandas fueron recogidas por diversos grupos de alumnos, siendo los de la Pontificia Universidad Católica de Valparaíso (PUCV) los primeros en solicitarlos, pero ante la ausencia que tuvieron de respuestas concretas planearon una toma el 19 de junio de 1967. Esto significó un precedente para los dirigentes de la Federación de estudiantes de la Universidad Católica (FEUC), dirigidos por Miguel Ángel Solar los cuales le plantearon al monseñor Alfredo Silva Santiago, que era el rector un petitorio con los cambios exigidos, ya que la PUC carecía de un plan general de desarrollo. Al no concretarse de manera rápida, la FEUC preparó lo que sería la toma del 11 de agosto.

Junto con relatar los detalles del movimiento y los roces que los huelguistas tuvieron con las facciones opositoras, García-Huidobro rescata los enfrentamientos que hubo entre Miguel Ángel Solar y el director del diario “El Mercurio” René Silva Espejo, ya que en sus páginas izquierdizó el movimiento, lo que valió la instalación de un cartel que decía "Chileno: El Mercurio miente”, marcando un hito por poner en tela de juicio la veracidad de la información que este medio entregaba.

Luego de esto, el autor menciona que el cardenal Raúl Silva Henríquez fue comisionado para gestionar el fin de la toma, por lo cual le exigió la renuncia a un reticente monseñor Silva Santiago, y se llamó a elecciones para la prorrectoría (administración provisional), en las que venció Fernando Castillo Velasco, el que posteriormente asumió como rector. Finalmente, menciona los posteriores avances en infraestructura e investigación que tuvo la PUC.

En el sexto de estos trabajos se construye la historia de la localidad de Rangue (ubicada en las cercanías de la laguna de Aculeo), para lo cual se utiliza una metodología distinta. En el, su autor Nicolás Ocaranza, utiliza los testimonios orales de sus habitantes más antiguos, con el propósito de contradecir el conocimiento que muchas veces ha servido de consenso para analizar la vida en el campo chileno.

Es así como Ocaranza recorre la historia del lugar, partiendo desde la época del latifundio, en la que sus territorios pertenecían a familias como los Letelier. También analiza algunos proyectos de parcelación de tierras 
tales como la Caja de Colonización Agrícola y la Reforma Agraria presente en los gobiernos de Jorge Alessandri, Eduardo Frei Montalva y Salvador Allende, el que fue interrumpido por el gobierno militar.

Su análisis lo termina con una serie de conclusiones críticas frente a los hechos ocurridos durante la dictadura, ya que menciona que muchos de los inquilinos que pretendieron ocupar terrenos parcelados fueron asesinados por agentes del gobierno militar. También resalta que el balance en la actualidad es desolador, ya que los antiguos inquilinos que lucharon por obtener tierras, ven ahora cómo estos han pasado a formar parte de la especulación de los empresarios y del interés de las inmobiliarias.

El libro finaliza con la investigación de Pablo Moscoso, la que busca analizar las protestas que hubo en contra del gobierno militar durante 1983, centrándose en el acto más que en la consecuencias, o como le llama el autor, estudiar "lo que pudo ser posible pero no fue". De esta forma, relata las jornadas de protesta organizadas por la Confederación de los trabajadores del cobre, en las que salía a relucir que la situación social y las críticas al modelo neoliberal que pusieron en jaque a la dictadura.

Junto a esto, menciona que el gobierno nombró a Sergio Onofre Jarpa como ministro del Interior, el cual tuvo la labor de dialogar con los líderes de los retornados partidos políticos una posible solución a las tensiones de ese año. Sin embargo, la estrategia del gobierno era dividir a la oposición, la cual se fragmentó entre el Movimiento Democrático Popular, de tendencia izquierdista, y la Alianza Democrática, que con los años se transformaría en la Concertación. Así, se privilegió una salida burocrática al conflicto en vez de seguir utilizando un manejo político de la violencia periférica, lo que provocó el retraso del retorno a la democracia por algunos años más.

A lo largo de estos artículos, podemos concluir que ellos realizan un gran aporte a la historiografía nacional al rescatar al siglo XX chileno, ya que es una época que ha sido postergada para analizar sucesos anteriores, debido a que estos no tienen los compromisos emocionales característicos de la historia reciente. Junto a esto, hay que resaltar las acuciosas investigaciones realizadas por estos siete jóvenes historiadores, ya que contienen una amplia variedad de fuentes y de enfoques, las que contribuyen a ampliar las perspectivas de las nuevas generaciones de historiadores.

Otra de las características que definen a este libro es el uso continuo de adjetivos y de juicios de valor, los que pueden despertar las críticas de los historiadores más convencionales. Sin embargo, el rigor investigativo y la calidad analítica que poseen los trabajos permiten justificar este tipo de licencias, las cuales le entregan ciertos rasgos novelescos a los artículos, generando una mayor empatía con los lectores.

De esta manera, y para finalizar, la presente obra presenta un marcado estilo narrativista, lo cual le permite generar mecanismos de apertura 
hacia un público mucho más amplio de lo habitual, gracias a la fluidez y simpleza de su lenguaje. Con esto, ellos demuestran que los trabajos historiográficos no necesitan ser investigaciones densas que se mantienen bajo el monopolio de unas minorías, sino que pueden elaborarse de manera cercana y dinámica, para así ser compartidos con todo el mundo. 